\title{
The role of nickel in the oxidation resistance of tungsten-based alloys
}

\author{
C. Louro *, A. Cavaleiro \\ ICEMS, Faculdade de Ciências e Tecnologia da Universidade de Coimbra, 3030 Coimbra, Portugal
}

\begin{abstract}
In this work, W-N-Ni coatings were produced with different contents of nickel and nitrogen. The films were oxidised in pure air at increasing temperatures up to $800^{\circ} \mathrm{C}$. An increase in the oxidation resistance upon the addition of an increasing amount of nickel was observed. The oxidation mechanism involves the formation of two nickel-rich, external oxide layers of $\mathrm{NiO}$ and $\mathrm{NiWO}_{4}$. The limiting step seems to be the outward diffusion of either $\mathrm{Ni}^{2+}$ or $\mathrm{W}^{6+}$ ions through the oxide layers. To retain the oxidation resistance of the amorphous $\mathrm{W}-\mathrm{N}-\mathrm{Ni}$ coatings at $800^{\circ} \mathrm{C}$, it is necessary that crystallisation does not induce a dimensional stress capable of destroying the protective oxide layers. C 1999 Elsevier Science S.A. All rights reserved.
\end{abstract}

Keywords: Coatings; Nickel; Oxidation; Sputtering

\section{Introduction}

Previous research works have shown that different oxide layers grow on the surface of tungsten sputtered films when they are oxidised in air in the temperature range 600 to $800^{\circ} \mathrm{C}$. It was demonstrated that the oxidation resistance of this sputtered film could be increased by alloying it with other transition metals (nickel or titanium) and/or interstitial elements (carbon or nitrogen). In the case of nickel, two coatings were studied: one without nitrogen and a very small nickel content showing a crystalline body-centred cubic (bcc) $\alpha-\mathrm{W}$ structure and the other, amorphous, with nitrogen and a higher nickel content. Despite the fact that in both cases the formation of the spinel phase $\mathrm{NiWO}_{4}$ was detected, their oxidation resistance was rather different. In the temperature range studied, $\mathrm{W}-\mathrm{N}-\mathrm{Ni}$ coatings showed a much better oxidation resistance than $\mathrm{W}-\mathrm{N} / \mathrm{C}$ and $\mathrm{W}-\mathrm{N} / \mathrm{C}-\mathrm{Ti}$ films [1-3].

In order to understand this behaviour, other $\mathrm{W}-\mathrm{N}-$ $\mathrm{Ni}$ coatings were produced with different contents of nickel and nitrogen. They were characterised before and after they had been subjected to oxidation annealing in air in the temperature range $600-800^{\circ} \mathrm{C}$.

\footnotetext{
* Corresponding author. Tel: +351-39-790745; fax: + 351-39-790701.

E-mail address: cristina.louro@mail.dem.uc.pt (C. Louro)
}

\section{Experimental}

\subsection{Deposition technique}

The films were deposited by direct-current (DC) reactive magnetron sputtering with a specific target power density of $10 \mathrm{~W} \mathrm{~cm}^{-2}$ and a negative substrate bias of $70 \mathrm{~V}$. To complement the series of $\mathrm{W}-\mathrm{N}-\mathrm{Ni}$ coatings previously described [1], the $\mathrm{W}-10 \mathrm{wt} \% \mathrm{Ni}$ target was used in reactive mode and two more films were deposited with an $\mathrm{N}_{2} / \mathrm{Ar}$ partial pressure ratio of $1 / 4$ and $1 / 3$, for a total deposition pressure of $0.3 \mathrm{~Pa}$. The substrates $(5 \mathrm{~mm} \times 5 \mathrm{~mm} \times 1 \mathrm{~mm})$ of steel (W1 AISI) were polished, finishing with a diamond paste of $1 \mu \mathrm{m}$. To completely coat the entire surface, the substrates were glued with precision on one of their lateral faces. Owing to the rotational movement of the substrate holder, all the faces were uniformly coated. Before deposition, the sputtering chamber was evacuated by a turbomolecular pump down to a final pressure of $10^{-4} \mathrm{~Pa}$. The substrate surfaces were then ion cleaned by an ion gun. The cleaning procedure included a first electron heating up to temperatures close to $450^{\circ} \mathrm{C}$ and afterwards $\mathrm{Ar}^{+}$-ion bombardment for $8 \mathrm{~min}$ (ion gun settings at $20 \mathrm{~A}, 40 \mathrm{~V}$, substrates at $-120 \mathrm{~V})$. The deposition time was selected such that a final thickness in the range $3-4 \mu \mathrm{m}$ could be obtained. 


\subsection{Characterisation techniques}

Thermogravimetric tests were carried out on a Polymer Science thermobalance of high resolution $(0.1 \mu \mathrm{g})$. Oxidation temperatures ranged from 600 to $800^{\circ} \mathrm{C}$. The samples were placed in the sample holder of the thermogravimetric equipment and heated up to the oxidation temperature at a fixed heating rate of $30^{\circ} \mathrm{C} \mathrm{min}^{-1}$. A constant isothermal time of $30 \mathrm{~min}$ was used. From the beginning of the procedure and during the entire test, industrial air of $99.995 \%$ purity flowing through a dehumidification unit was introduced into the furnace with a flow rate of $55 \mathrm{~cm}^{3} \mathrm{~min}^{-1}$.

The results of the oxidation tests are presented later in the text as the alterations in the weight gain as a function of the oxidation temperature/time. The weight gain is normalised by dividing the weight changes, during the oxidation tests, by the total area of the sample surfaces.

The structure of the films was analysed by X-ray diffraction (XRD) using a Siemens diffractometer with $\mathrm{Cu} \mathrm{K} \alpha$ radiation.

A Cameca SX-50 electron probe microanalysis (EPMA) apparatus was used to determine the chemical composition of the coatings.

The cross-section of the films (obtained by fracturing the coated samples), their surface topology and morphological details were examined by scanning electron microscopy (SEM) in a Jeol T330 instrument operated at $20 \mathrm{kV}$ and at $0-15^{\circ}$ view. This apparatus was connected to an energy-dispersive X-ray detector (EDXS) (Tracor Instruments) which allowed an easy check for the presence of chemical elements of interest at different points of the SEM images.

\section{Results}

\subsection{Characterisation of the as-deposited films}

Results concerning the chemical composition, structure and morphology of as-deposited $\mathrm{W}-\mathrm{N}-\mathrm{Ni}$ films are presented in Table 1. Data for W-(N)-Ni films obtained in previous work [1] are also presented. The chemical composition values were normalised to 100 at\% for tungsten, nickel and nitrogen. However, vestiges of argon, carbon and oxygen $(<3$ at $\%)$ were also detected. The use of increasing $\mathrm{N}_{2} / \mathrm{Ar}$ partial pressure ratio led not only to an increasing nitrogen content but also to an increasing $\mathrm{Ni} / \mathrm{W}$ ratio in the films. In all cases the $\mathrm{Ni} / \mathrm{W}$ ratio was always inferior to that of the target. The difference is related to the preferential resputtering of nickel during the deposition induced by the negative substrate bias. In fact, when a multielemental material is bombarded, the lighter element (nickel) is preferentially sputtered compared with the other elements (tungsten) [4]. When nitrogen is present (the lightest element) this phenomenon is attenuated and the preferential resputtering of nickel is not so evident.

As-deposited coatings with nickel contents lower than 10 at $\%$ present the bcc $\alpha-\mathrm{W}$ tungsten phase [5]. For higher nickel values, amorphous structures characterised by two broad XRD peaks are detected (Fig. 1). This threshold value, for the content of nickel, was a little higher than that obtained by other authors for the W$\mathrm{C}-\mathrm{Ni}$ system [6] probably due to its higher carbon content $(>40$ at $\%)$ than the nitrogen content in this work. These researchers confirmed that amorphisation of the ( $\mathrm{W}-\mathrm{C})$-based films produced by sputtering could be obtained by the addition of a Group VIII transition

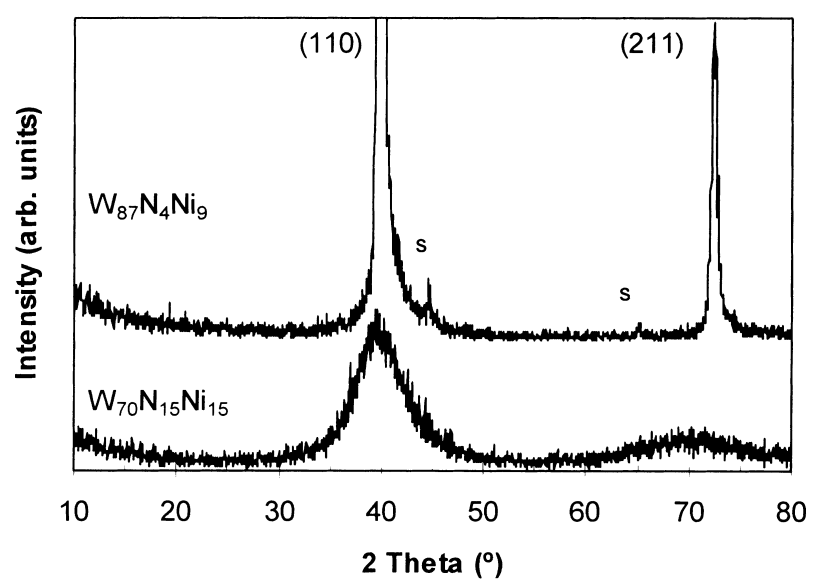

Fig. 1. X-ray diffractograms of as-deposited coatings: $\mathrm{W}_{87} \mathrm{~N}_{4} \mathrm{Ni}_{9} \rightarrow$ $\alpha-\mathrm{W}$ phase; $\mathrm{W}_{70} \mathrm{~N}_{15} \mathrm{Ni}_{15} \rightarrow$ amorphous phase; $\mathrm{s}=$ substrate.

Table 1

Chemical composition, structure and morphology results of as-deposited sputtered $\mathrm{W}-\mathrm{N}-\mathrm{Ni}$ films

\begin{tabular}{|c|c|c|c|c|c|c|}
\hline \multirow[t]{2}{*}{ Film } & \multirow[t]{2}{*}{$\mathrm{N}_{2} /$ Ar ratio } & \multicolumn{3}{|c|}{ Chemical composition (at\%) } & \multirow[t]{2}{*}{ Structure } & \multirow[t]{2}{*}{ Morphology } \\
\hline & & $\mathrm{W}$ & $\mathrm{N}$ & $\mathrm{Ni}$ & & \\
\hline $\mathrm{W}_{98} \mathrm{Ni}_{2}^{\mathrm{a}}$ & - & 98.3 & - & 1.7 & $\alpha-W$ & 1 \\
\hline $\mathrm{W}_{87} \mathrm{~N}_{4} \mathrm{Ni}_{9}$ & $1 / 4$ & 87.3 & 3.4 & 9.3 & $\alpha-\mathrm{W}$ & 1 \\
\hline $\mathrm{W}_{70} \mathrm{~N}_{15} \mathrm{Ni}_{15}$ & $1 / 3$ & 70.0 & 14.7 & 15.3 & Amorphous & $\mathrm{T}$ \\
\hline $\mathrm{W}_{66} \mathrm{~N}_{18} \mathrm{Ni}_{16}^{\mathrm{a}}$ & $1 / 2$ & 66.2 & 18.3 & 15.5 & Amorphous & $\mathrm{T}$ \\
\hline
\end{tabular}

${ }^{\mathrm{a}}$ Data from previous research work [1]. 
metal. The synergetic effect of nitrogen and nickel in the production of amorphous structures was also demonstrated for a composition $\mathrm{W}_{49} \mathrm{~N}_{21} \mathrm{Ni}_{30}$ during a study on the influence of nitrogen during co-sputtering of nickel and tungsten films [7].

The crystalline coatings have columnar type 1 morphology [8] while the amorphous films present a more compact morphology which can be classified as very dense $\mathrm{T}$ type or featureless (Fig. 2). This is an expected result taking in account the work of Dirks et al. [9], who showed an increase in the compactness of sputtered coatings with the introduction of nitrogen. Amorphous $\mathrm{W}-\mathrm{N}-\mathrm{Ni}$ films have higher nitrogen contents than crystalline ones.

\subsection{Isothermal oxidation behaviour}

The isothermal mass-change data for $\mathrm{W}-\mathrm{N}-\mathrm{Ni}$ coatings at 700,750 and $800^{\circ} \mathrm{C}$ are presented in Fig. 3. For comparison, owing to its nickel content, data concerning the $\mathrm{W}_{98} \mathrm{Ni}_{2}$ and $\mathrm{W}_{66} \mathrm{~N}_{18} \mathrm{Ni}_{16}$ [1] sputtered coatings are also included.

Analysis of the oxidation resistance up to temperatures of $750^{\circ} \mathrm{C}$ allows one to conclude that increasing nickel contents in the films give rise to increasing oxida-

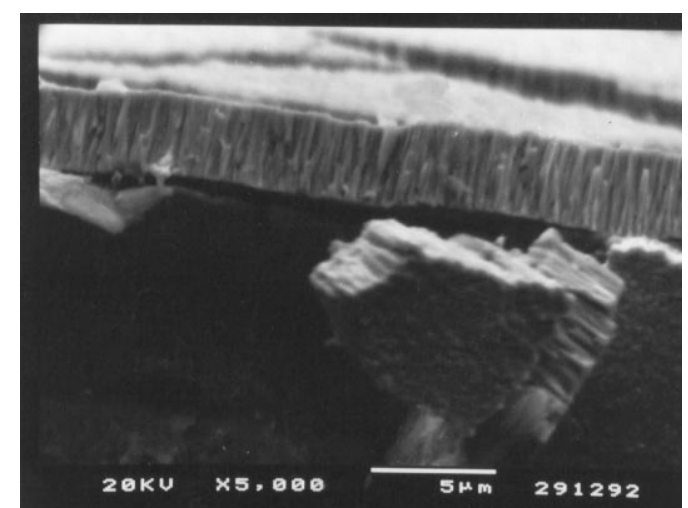

(a)

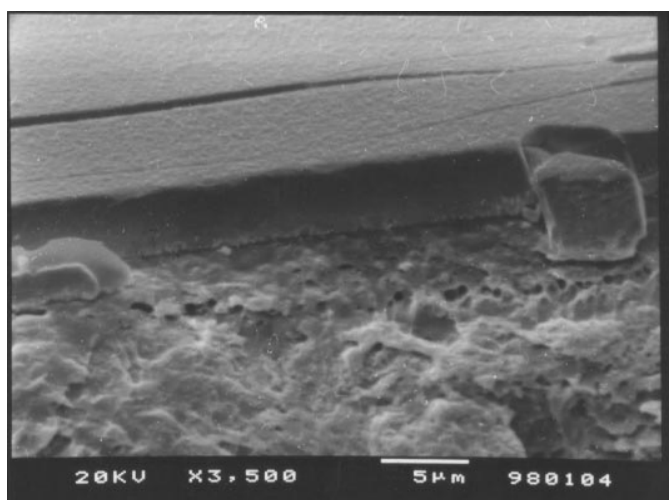

(b)

Fig. 2. SEM micrographs of the cross-sections of $\mathrm{W}-\mathrm{N}-\mathrm{Ni}$ as-deposited films: (a) $\mathrm{W}_{87} \mathrm{~N}_{4} \mathrm{Ni}_{9}$; (b) $\mathrm{W}_{70} \mathrm{~N}_{15} \mathrm{Ni}_{15}$.
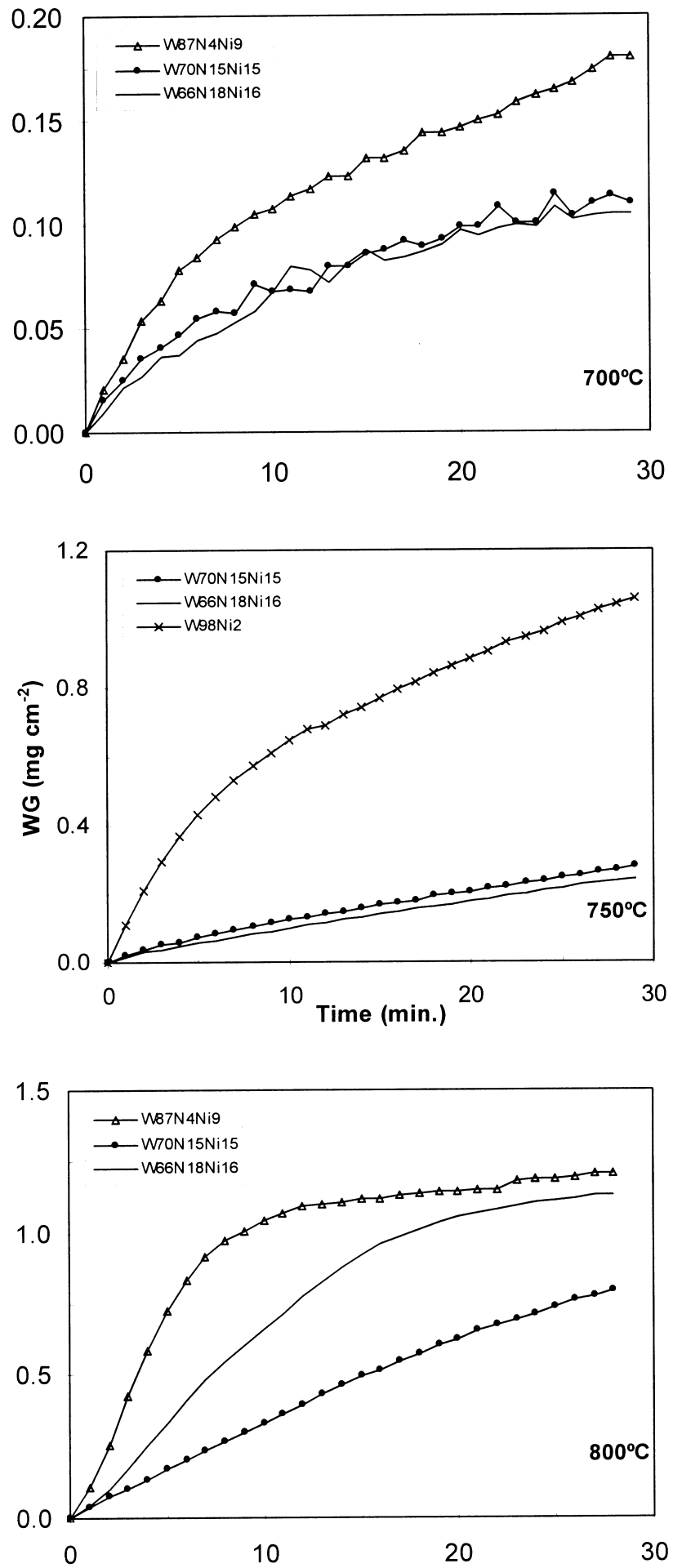

Fig. 3. Isothermal oxidation curves of the $\mathrm{W}-\mathrm{N}-\mathrm{Ni}$ coatings in air.

tion resistance. At $800^{\circ} \mathrm{C}$ an inversion was observed for the coatings $\mathrm{W}_{70} \mathrm{~N}_{15} \mathrm{Ni}_{15}$ and $\mathrm{W}_{66} \mathrm{~N}_{18} \mathrm{Ni}_{16}$. Moreover, it is observed that the saturation of the weight gain curve corresponding to substrate oxidation is not constant for all the coated samples.

Fig. 4 shows the X-ray diffractograms obtained at 

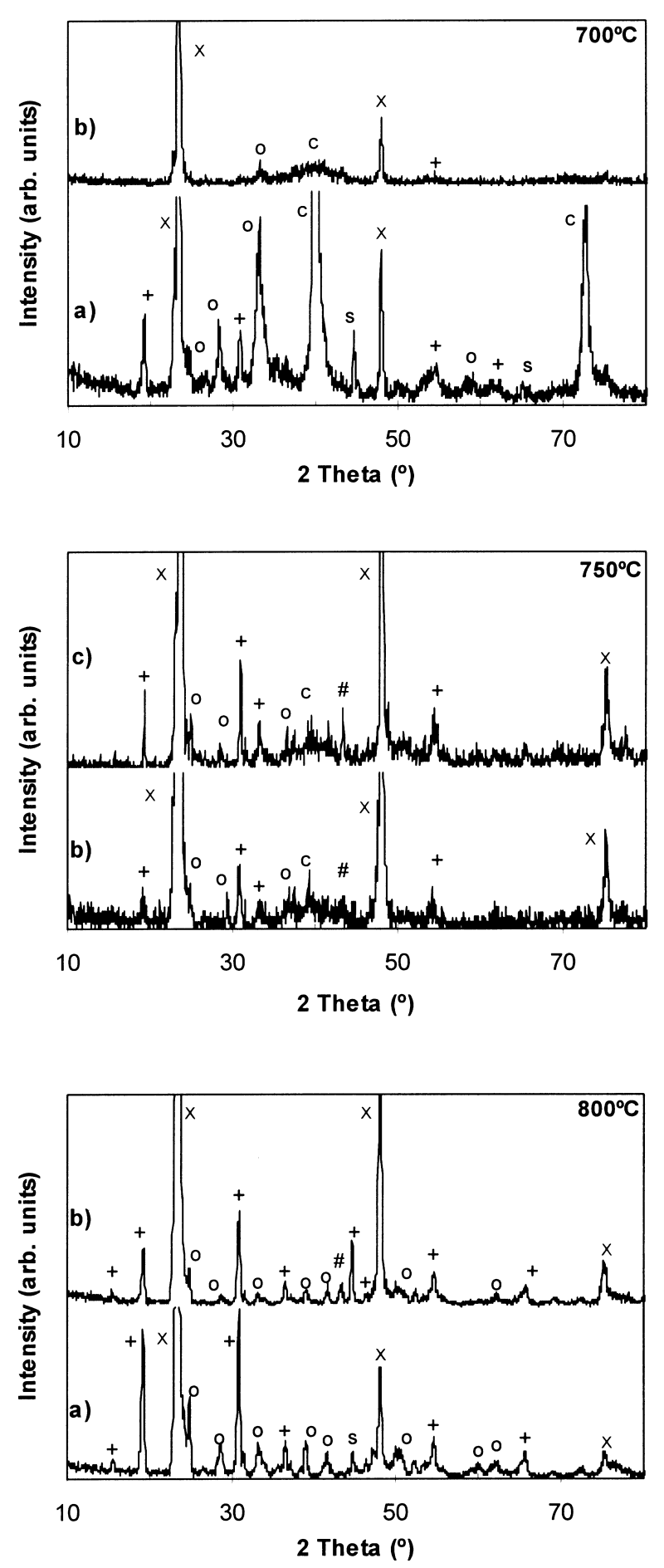

Fig.4. Structural evolution of the $\mathrm{W}-\mathrm{N}-\mathrm{Ni}$ films with oxidation temperature: (a) $\mathrm{W}_{87} \mathrm{~N}_{4} \mathrm{Ni}_{9}$; (b) $\mathrm{W}_{70} \mathrm{~N}_{15} \mathrm{Ni}_{15}$; (c) $\mathrm{W}_{66} \mathrm{~N}_{18} \mathrm{Ni}_{16}$. $\bigcirc=\mathrm{WO}_{3}$, $\mathrm{X}=\mathrm{WO}_{x},+=\mathrm{NiWO}_{4}, \#=\mathrm{NiO}, \mathrm{s}=$ substrate, $\mathrm{c}=$ unoxidised coating.

increasing oxidation temperatures for the $\mathrm{W}_{87} \mathrm{~N}_{4} \mathrm{Ni}_{9}$ and $\mathrm{W}_{70} \mathrm{~N}_{15} \mathrm{Ni}_{15}$ coatings. The differences between both samples are not significant, although some points should be remarked upon. First, in both oxidised samples, the tungsten oxides $\mathrm{WO}_{x}$ and $\mathrm{WO}_{3}[10]$ are observed, the first being much more evident particularly for the lower oxidation temperatures. Second, at $700^{\circ} \mathrm{C}$, the $\mathrm{NiWO}_{4}$ [11] phase is also present. Finally, for $800^{\circ} \mathrm{C}$, a distinct peak (although already present in previous work for the $\mathrm{W}_{66} \mathrm{~N}_{18} \mathrm{Ni}_{16}$ film at $750^{\circ} \mathrm{C}$ oxidation temperature see Fig. 4) indexed as $\mathrm{NiO}$ [11] is observed for the $\mathrm{W}_{70} \mathrm{~N}_{15} \mathrm{Ni}_{15}$ oxidised film.

In agreement with the different phases indexed, analysis of the surface and cross-sectional morphologies of the oxidised samples allowed the identification of several layers with different chemical composition. The $\mathrm{W}_{87} \mathrm{~N}_{4} \mathrm{Ni}_{9}$ sample presents accelerated oxidation in particular zones for temperatures of $700^{\circ} \mathrm{C}$ [Fig. 5(a)]. The degradation is complete for higher temperatures, it being possible to observe also different layers at the interface between the oxidised films and the substrate [Fig. 5(b)]. In spite of its low lateral resolution, the use of EDXS allowed us to identify the variation in elemental concentration in the different layers. Thus, in the top layer (A), a high nickel content was measured whereas in the other layers its amount is almost nil. Iron was detected in all the oxide layers, suggesting its diffusion upwards from the substrate. However, its amount does not increase uniformly from the substrate to the exterior; layer $\mathrm{C}$ has a higher iron content than layer $\mathrm{D}$.

Conversely to this film, $\mathrm{W}_{70} \mathrm{~N}_{15} \mathrm{Ni}_{15}$ does not present iron in the oxidised layers. Moreover, the accelerated oxidation is only detected in a few points at $750^{\circ} \mathrm{C}$, it being extended for $800^{\circ} \mathrm{C}$ [Fig. 5(c)]. However, it should be remarked that outside these points unoxidised coating is still observed [Fig. 5(d)]. The nickel profile in these areas is: top layer - high content; intermediate layer almost no nickel; bottom layer - nickel amounts close to the as-deposited value.

\section{Discussion}

In comparison with previous results [1], this study confirms that the presence of nickel improves the oxidation resistance of $\mathrm{W}-(\mathrm{N})$ sputtered coatings. The improvement is higher for higher nickel contents. Detection of the NiO phase (although only one diffraction peak is undoubtedly found) as an oxidation product of the $\mathrm{W}_{70} \mathrm{~N}_{15} \mathrm{Ni}_{15}$ film has clarified the mechanism of oxide growth. Confirmation of the formation of this phase was done by Auger electron spectroscopy (AES). Fig. 6 presents, for the $\mathrm{W}_{70} \mathrm{~N}_{15} \mathrm{Ni}_{15}$ coating oxidised at $700^{\circ} \mathrm{C}$, the relationship between the Auger intensity of signals for tungsten, nickel, oxygen and nitrogen as a function of the erosion time. It should be remarked that these results are presented without the application of any type of intensity factors allowing the determination of elemental composition. Thus, only the evolution in each curve should be considered. This figure confirms the existence of a surface layer very rich in nickel and oxygen, without tungsten. Under this layer, the increase 


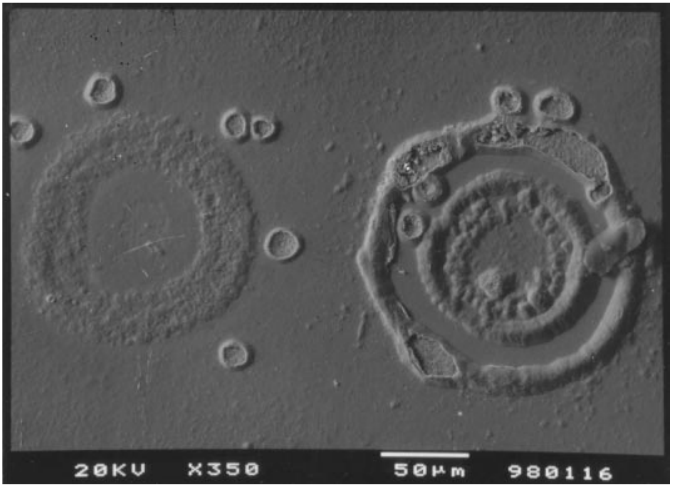

(a)

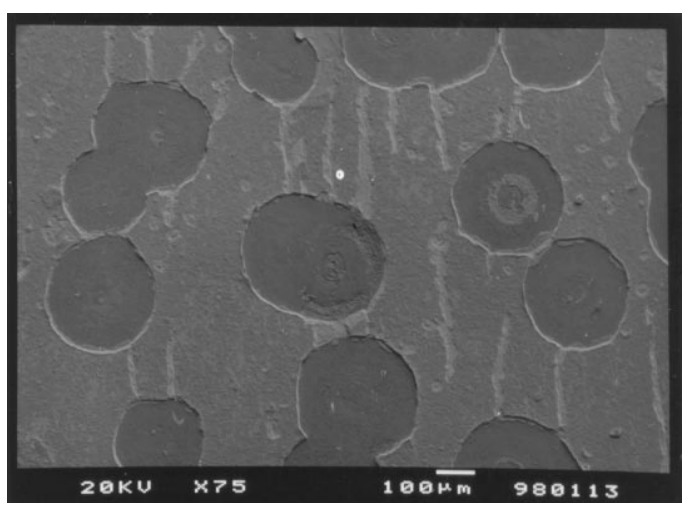

(c)

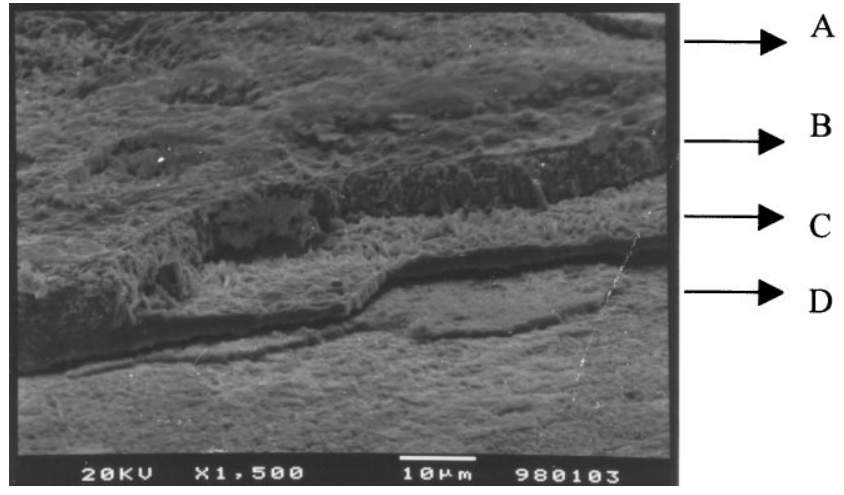

(b)

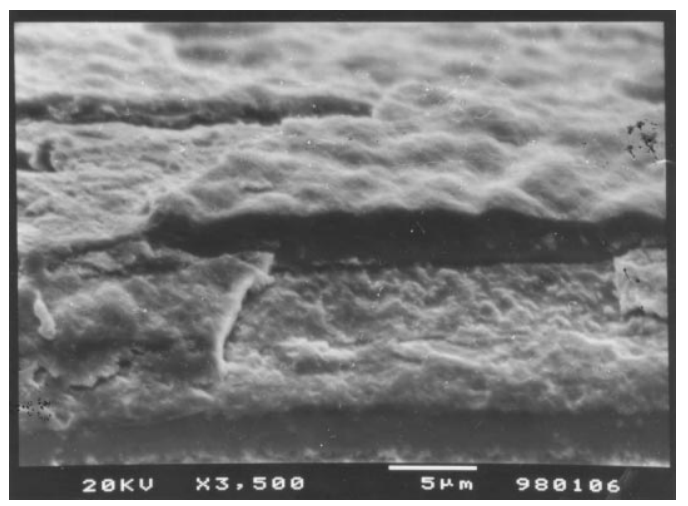

(d)

Fig. 5. SEM micrographs of $\mathrm{W}-\mathrm{N}-\mathrm{Ni}$ films after they have been oxidised for 30 min: (a) surface of the $\mathrm{W}_{87} \mathrm{~N}_{4} \mathrm{Ni}_{9}$ film (700 ${ }^{\circ} \mathrm{C}$ ); (b) cross-section of the $\mathrm{W}_{87} \mathrm{~N}_{4} \mathrm{Ni}_{9}$ film $\left(800^{\circ} \mathrm{C}\right)$; (c) surface of the $\mathrm{W}_{70} \mathrm{~N}_{15} \mathrm{Ni}_{15}$ film $\left(800^{\circ} \mathrm{C}\right)$; (d) cross-section of the $\mathrm{W}_{70} \mathrm{~N}_{15} \mathrm{Ni}_{15}$ film (800 $\left.{ }^{\circ} \mathrm{C}\right)$. A, external layer with high nickel content; $\mathrm{B}$, intermediate layer without nickel content; $\mathrm{C}$, internal layer with high iron content; $\mathrm{D}$, lower iron content than in layer $\mathrm{C}$.

of the tungsten signal is observed with the decrease of the nickel signal until its annihilation. This zone corresponds to the tungsten oxide layers which, as already demonstrated by EDXS, do not contain nickel. Finally, the nickel signal increases (also with nitrogen) against the strong decrease of oxygen; i.e., the unoxidised part of the coating is reached.

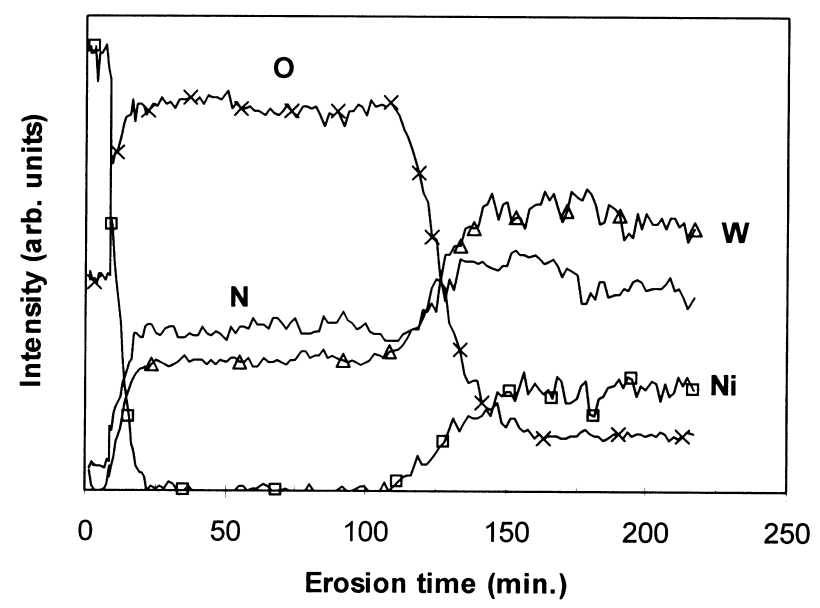

Fig. 6. AES depth profiles of the $\mathrm{W}_{70} \mathrm{~N}_{15} \mathrm{Ni}_{15}$ coating oxidised at $700^{\circ} \mathrm{C}, 30 \mathrm{~min}$.
Thus, besides the oxide layers $\left(\mathrm{WO}_{\mathrm{x}}, \mathrm{WO}_{3}, \mathrm{NiWO}_{4}\right)$ already referred to before, the $\mathrm{NiO}$ phase should also be considered. If so, the scheme shown in Fig. 7 will describe better the arrangement of the oxide layer. This

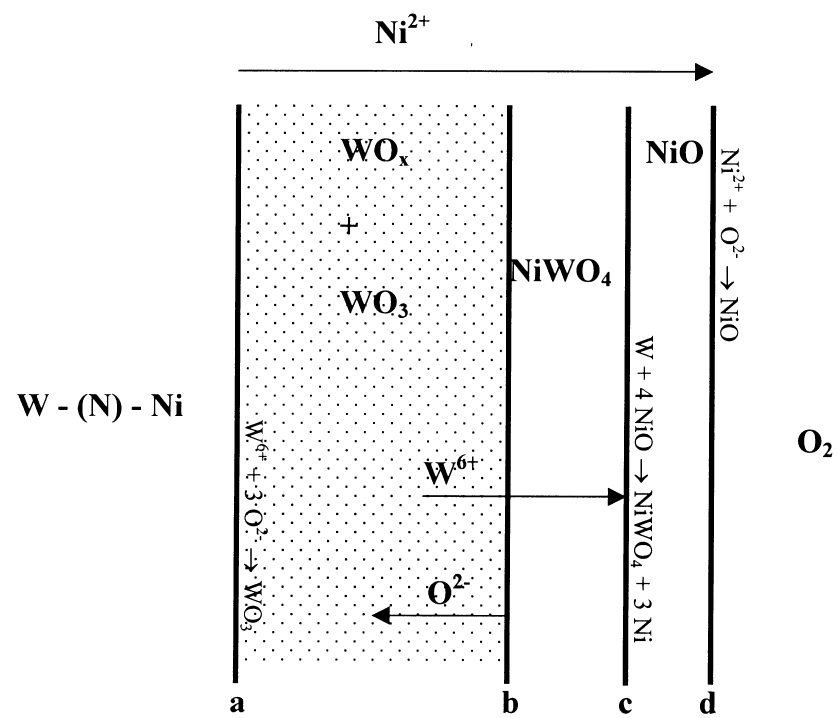

Fig. 7. Scheme of the mechanism involved in the oxidation process of W-N-Ni sputtered films. 
is very close to the work of Brenner et al. [12] concerning the oxidation of $\mathrm{Ni}-\mathrm{Mo}(\mathrm{W})$ alloys. The mechanism of oxide growth can be described as follows.

- Owing to the higher affinity of tungsten for oxygen, it is preferentially oxidised as $\mathrm{WO}_{x}$. As this process occurs the nickel is depleted from the surface, being oxidised and forming a continuous layer of $\mathrm{NiO}$.

- As $\mathrm{NiO}$ is a p-type semiconductor it grows by the simultaneous diffusion of nickel ions via cation vacancies and electron holes. Thus, access to the oxygen should be through the $\mathrm{NiO}$ layer. Tungsten can combine with $\mathrm{NiO}$ to form $\mathrm{NiWO}_{4}$. This mixed oxide is an intermediate layer between $\mathrm{NiO}$ and the single tungsten oxides.

- For the progression of the oxidation it is necessary that $\mathrm{Ni}^{2+}$ ions diffuse outwards through three layers $\left(\mathrm{WO}_{x}, \mathrm{NiWO}_{4}\right.$ and $\left.\mathrm{NiO}\right)$ to combine at interface d with oxygen. At the same time, $\mathrm{W}^{4+}$ ions also diffuse outwards through $\mathrm{NiWO}_{4}$ to combine with the oxygen of $\mathrm{NiO}$ at interface c $(\mathrm{W}+4 \mathrm{NiO} \rightarrow$ $\mathrm{NiWO}_{4}+3 \mathrm{Ni}$ ). In the meanwhile, oxygen diffuses into the interior from the interface $\mathbf{b}$, the driving force being the difference between the dissociation pressure of $\mathrm{NiWO}_{4}$ and the oxygen partial pressure in the $\mathrm{W}-(\mathrm{N})-\mathrm{Ni}$ film.

- For the growth of oxide layers from the remaining unoxidised film, it is necessary to have available oxygen at interface $\mathbf{b}$, and this is only possible if both nickel (from the film and from the interface c) and tungsten ions diffuse outwards.

In consequence, if the amount of nickel in the as-deposited film is high, for the same quantity of single tungsten oxide formed then thicker $\mathrm{NiO}$ and $\mathrm{NiWO}_{4}$ layers exist as compared with the films with lower nickel content. The outward diffusion of nickel and tungsten is more difficult and less oxygen will be available at interface $\mathbf{c}$ to proceed with the oxidation, leading to lower oxidation rates.

Analysis of the weight gain curves leads to the conclusion that parabolic behaviours could be found for some parts of the oxidation process. For the beginning of oxidation (low oxidation temperatures and/or small oxidation times) it was possible to determine an apparent activation energy in the range 180 $210 \mathrm{~kJ} \mathrm{~mol}^{-1}$. An increase to higher values of $265-295 \mathrm{~kJ} \mathrm{~mol}^{-1}$ was observed for the remaining part of the process. This behaviour, found previously for the oxidation of $\mathrm{W}-\mathrm{C}-\mathrm{Ni}$ [3], suggests two different mechanisms for oxide growth in agreement with that presented above. The first values are close to those determined for the oxidation of single-phase tungsten and $\mathrm{W}-\mathrm{N}$ sputtered films [1]. The second values should be attributed to the diffusion of $\mathrm{Ni}^{2+}$ through the $\mathrm{NiO}$ or $\mathrm{NiWO}_{4}$, or the diffusion of $\mathrm{W}^{6+}$ through $\mathrm{NiWO}_{4}$. In the literature, the oxidation of nickel gives rise to very different values of activation energy $\left(160-280 \mathrm{~kJ} \mathrm{~mol}^{-1}\right)$ [13], some of them being in the range of those found for the oxidation of $\mathrm{W}-\mathrm{N}-\mathrm{Ni}$ samples.

At $800^{\circ} \mathrm{C}$ an unexpected behaviour was observed the $\mathrm{W}_{70} \mathrm{~N}_{15} \mathrm{Ni}_{15}$-coated sample shows lower weight gains than the $\mathrm{W}_{66} \mathrm{~N}_{18} \mathrm{Ni}_{16}$-coated sample in spite of its lower nickel content. In a previous paper we attributed the bad oxidation behaviour of the $\mathrm{W}_{66} \mathrm{~N}_{18} \mathrm{Ni}_{16}$ film to its crystallisation during the oxidation process [2]. The dimensional variation, a consequence of the amorphous $\rightarrow$ crystalline transformation, was sufficient to induce a stress field capable of leading to spallation of the protective oxide and increasing the oxidation rate. In order to try to understand why this fact is not observed for amorphous $\mathrm{W}_{70} \mathrm{~N}_{15} \mathrm{Ni}_{15}$, we studied its thermal stability at increasing temperatures. Fig. 8 shows the X-ray diffractograms for the vacuum-annealed sample.

In comparison with the previous study some differences can be observed between the two samples. First, in this case, the crystallisation begins at $700^{\circ} \mathrm{C}$ as opposed to $750^{\circ} \mathrm{C}$ for the $\mathrm{W}_{66} \mathrm{~N}_{18} \mathrm{Ni}_{16}$ sample. Second, the main phase formed by crystallisation is the bcc $\alpha-\mathrm{W}$ instead of the $\mathrm{W}_{2} \mathrm{~N}$ nitride of the other study. We think that both these facts lead to a more progressive crystallisation with better adaptation of the stresses induced by the amorphous $\rightarrow$ crystalline transformation. In fact, the problem of oxide spallation seems to be due to sudden dimensional variations. As can be observed in Fig. 9, the oxidation resistance of the $\mathrm{W}_{66} \mathrm{~N}_{18} \mathrm{Ni}_{16}$ sample after it has been submitted to a vacuum thermal annealing (crystalline structure) is much better than that of the original amorphous sample and even better than that presented by the $\mathrm{W}_{70} \mathrm{~N}_{15} \mathrm{Ni}_{15}$ coating. This is in agreement with the influence of the nickel content on the oxidation behaviour as presented above. The difference between the crystalline and amorphous samples with respect the oxidation process is only that, in the first case, the

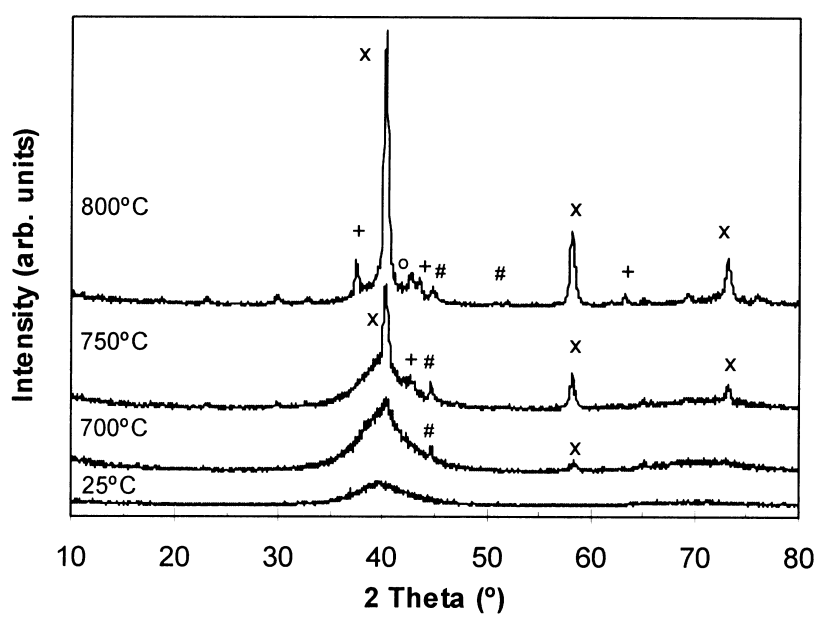

Fig. 8. XRD diffractograms of the $\mathrm{W}_{70} \mathrm{~N}_{15} \mathrm{Ni}_{15}$ film taken at increasing vacuum annealing temperatures; $x=\alpha-\mathrm{W},+=\mathrm{W}_{2} \mathrm{~N}, \#=\mathrm{Ni}, \bigcirc=$ $\mathrm{M}_{6} \mathrm{C}$ (due to the residual carbon of the coating). 


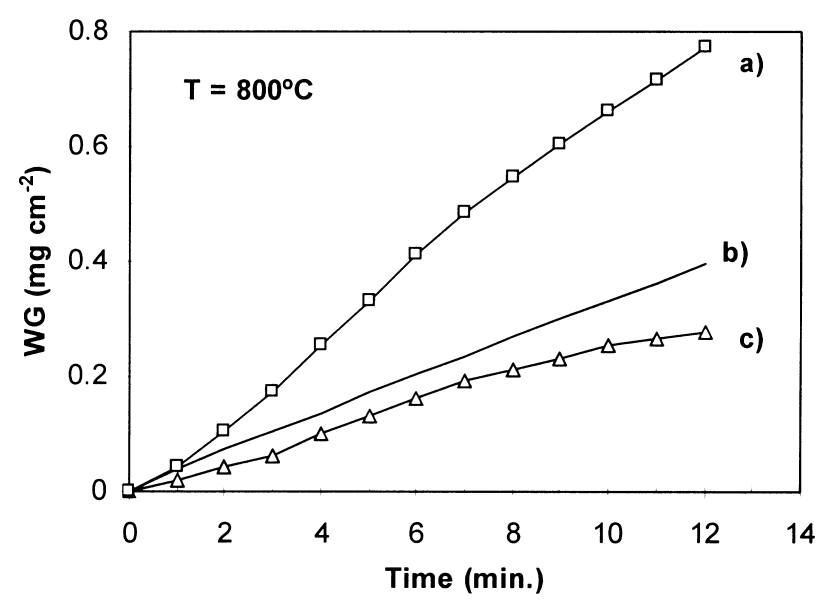

Fig. 9. Isothermal oxidation plot for sputtered $\mathrm{W}-\mathrm{N}-\mathrm{Ni}$ films: (a) $\mathrm{W}_{66} \mathrm{~N}_{18} \mathrm{Ni}_{16}$; (b) $\mathrm{W}_{70} \mathrm{~N}_{15} \mathrm{Ni}_{15}$; (c) $\mathrm{W}_{66} \mathrm{~N}_{18} \mathrm{Ni}_{16}$ previously crystallised by vacuum thermal annealing.

protective oxide layers are not submitted to any sudden increase of stress; they remain adherent to the unoxidised film and contribute to a lower oxidation rate.

The synergetic action of both nickel and nitrogen is also very important in avoiding the interdiffusion of film and substrate elements. As was pointed out by Zhu et al. [7,14], films containing nitrogen are more efficient in preventing the diffusion of nickel to the substrate than films without nitrogen. The presence of iron in the oxidised layers, for the highest temperatures studied in the case of films with low nickel content, shows the upwards diffusion of this element. It is worth remarking that, after iron diffusion, the oxidation process of the $\mathrm{W}-\mathrm{Fe}$ mixed zone seems to be similar to that described for $\mathrm{W}-\mathrm{N}-\mathrm{Ni}$. In fact, by EDXS it was possible to detect a more external oxide layer with higher iron content than the other close to the steel substrate [Fig. 5(b)]. This also indicates the upwards diffusion of iron and its depletion in the intermixed $\mathrm{W}-\mathrm{Fe}$ zone.

\section{Conclusions}

- The addition of nickel to sputtered tungsten-based coatings improves their oxidation resistance, the improvement increasing with increasing nickel content.

- In the oxidised coatings it is possible to demonstrate the presence of two external oxide layers rich in nickel $\left(\mathrm{NiO}\right.$ and $\mathrm{NiWO}_{4}$ ), one sub-layer of a single tungsten oxide without nickel and, in the case of films with low $\mathrm{Ni} / \mathrm{N}$ ratio, an external layer of mixed iron and tungsten oxides.

- Several fluxes of ions were considered to take place during the oxidation: the outward diffusion of both $\mathrm{Ni}^{2+}$ (through all the oxide layers) and $\mathrm{W}^{6+}$ (through the spinel oxide) ions and the inward diffusion of $\mathrm{O}^{2-}$ ions through the layers of single tungsten oxide.

- At $800^{\circ} \mathrm{C}$ the oxidation resistance of the amorphous $\mathrm{W}-\mathrm{N}-\mathrm{Ni}$ coatings is only retained if crystallisation does not give rise to dimensional variations sufficient to induce destruction of the protective external oxide layer.

\section{References}

[1] C. Louro, A. Cavaleiro, J. Electrochem. Soc. 144 (1997) 259.

[2] C. Louro, A. Cavaleiro, Surf. Coat. Technol. 74-75 (1995) 998.

[3] C. Louro, A. Cavaleiro, J. Mat. Proc. Technol., in press.

[4] H.F. Winters, J. Vac. Sci. Technol. 3 (1982) 493.

[5] Joint Committee on Powder Diffraction Standards, Powder Diffraction File, Card 4-0806, International Centre for Diffraction Data, Swarthmore, PA.

[6] B. Trindade, M.T. Vieira, E. Bauer-Grosse, Thin Solid Films 252 (1994) 82.

[7] M.F. Zhu, F.C.T. So, M.-A. Nicolet, Thin Solid Films 130 (1985) 245.

[8] J.A. Thornton, Annu. Rev. Mater. Sci. 7 (1977) 239.

[9] A.G. Dirks, R.A.M. Wolters, A.E.M. Veirman, Thin Solid Films 208 (1992) 181.

[10] Joint Committee on Powder Diffraction Standards, Powder Diffraction File, Cards 5-0392, 36-0101, 5-0058, 5-0386, 36-0103, 20-1323, 20-1324, 24-074, 32-1394, 32-1395, 33-1387 and 41-0369, International Centre for Diffraction Data, Swarthmore, PA.

[11] Joint Committee on Powder Diffraction Standards, Powder Diffraction File, Cards 15-0755 and 4-0835, International Centre for Diffraction Data, Swarthmore, PA.

[12] S.S. Brenner, J. Electrochem. Soc. 102 (1955) 7.

[13] K. Fueki, B. Wagner Jr., J. Electrochem. Soc. 112 (1965) 384.

[14] M.F. Zhu, I. Suni, M.-A. Nicolet, J. Appl. Phys. 56 (1984) 2740. 